\title{
Clean and sustainable electric energy in Romania
}

\author{
C. A. $\operatorname{Safta}^{1}$, A. M. Marinov ${ }^{1}$, G. E. Dumitran ${ }^{1}$ \& B. Popa ${ }^{1,2}$ \\ ${ }^{I}$ Department of Hydraulics, Hydraulic Machinery and Environmental \\ Engineering, Faculty of Power Engineering, \\ University Politehnica of Bucharest, Romania \\ ${ }^{2}$ Romanian Small Hydropower Association, Romania
}

\begin{abstract}
UE policies have played a leading role in protecting the environment by reducing emissions of greenhouse gases, and minimizing environmental impacts of energy use. Romanian National Renewable Energy Action Plan (NREAP) has promoted the use of energy from renewable sources in accordance with the Directive 2009/28/EC of the European Parliament. In this regard, renewable energy resources appear to be the one of the most efficient and effective solutions for clean and sustainable energy development in Romania. Despite the current economic downturn, electricity consumption in Romania for 2014-2020 is expected to have a growth of $2-3 \%$ per year, estimating a $4.6 \%$ gross domestic production (GDP). Romania's potentials for electricity generation from renewable resources is represented by: hydro energy with a theoretical potential estimated to $40 \mathrm{TWh}$ in hydro power plant with more than $10 \mathrm{MW}$ and $6 \mathrm{TWh}$ in the small ones; wind energy with a theoretical potential estimated to $23 \mathrm{TWh}$ and photovoltaic energy estimated to 1.2 TWh (source Romanian NREAP).

From estimations and theoretical figures to reality regarding renewable energy in Romania the evolution is spectacular because in 2007 the hydro electric energy production was representative with $15.7 \%$ and renewables were no longer mentioned, and in 2013 (04.03.3013), the figures were 30.0\% in hydro power and 6.5\% wind (www.transelectrica.ro). According to NREAP, the expectations in the wind energy installed capacity were 1,850 MW in 2012 and the real installed capacity was $1,905 \mathrm{MW}$, with $3 \%$ growth. This paper deals with present and future prospect situation of renewable energy and the role of hydropower in Romania. This study shows that there is an important potential for
\end{abstract}


renewable energy in Romania, especially concerning hydropower, and wind energy. We analyze the renewable energy sources in Romania considering the most important criteria for sustainable development.

Keywords: renewable energy, small hydropower, wind power, photovoltaic, sustainable development, environmental impact.

\section{Introduction}

The energy sector was reported to be one of the main producers of greenhouse gases in 2007, at the level of European Union [1]. With respect to global environmental issues, UE's carbon dioxide emissions have grown along with its energy consumption. Under these circumstances, Romanian energy policy for 2007-2020 has as strategic targets the sustainable development of electricity generation sector [2]. Thus, promoting the electric energy generation from renewable resources, reducing the negative impact of energy sector on environment, and rational and efficient use of primary energy resources are some of the sustainable development goals. Therefore, according to national targets assumed by Romania, the share of electric energy generated from renewable sources, in gross electricity consumption, should be of $35 \%$ in 2015 and of $38 \%$ in 2020 .

Green energy technologies (especially hydropower plants, wind farms, photovoltaic farms) promise attractive non-polluting alternatives to reduce the current dependence on fossil and nuclear-fuelled power plant to cope with the growing demand of electrical energy.

The most important objective functions for the renewable energy technology considered like a system are: education in energy-related greenhouse gas emissions; more widely protection for the environment; energy security; energy service cost minimization for both business and residential consumers; energy service accessibility.

In the context of climate change mitigation, energy systems need to be examined and reshaped to ensure efficiency improvement [3]. To increase the efficiency with which energy is extracted or captured, converted, and utilized, is necessary to improve the current technology, to develop new transformative ones, to improve the management and coordination of energy institutions (public, private or mixed enterprises)

This paper aims to illustrate the way Romania succeeded to have significant growth in installing new energy capacities using renewable sources of energy, during 2005-2012 and the impact on the environment, for each type of renewable energy technology used to generate electricity.

\section{Renewable energy sources in Romania}

Even so, Romanian demand for energy and electricity decreased in the last five years (fig. 1), environmental pollution is becoming an important concern heavily dependent on a big percent of fossil energy from the total installed one. 


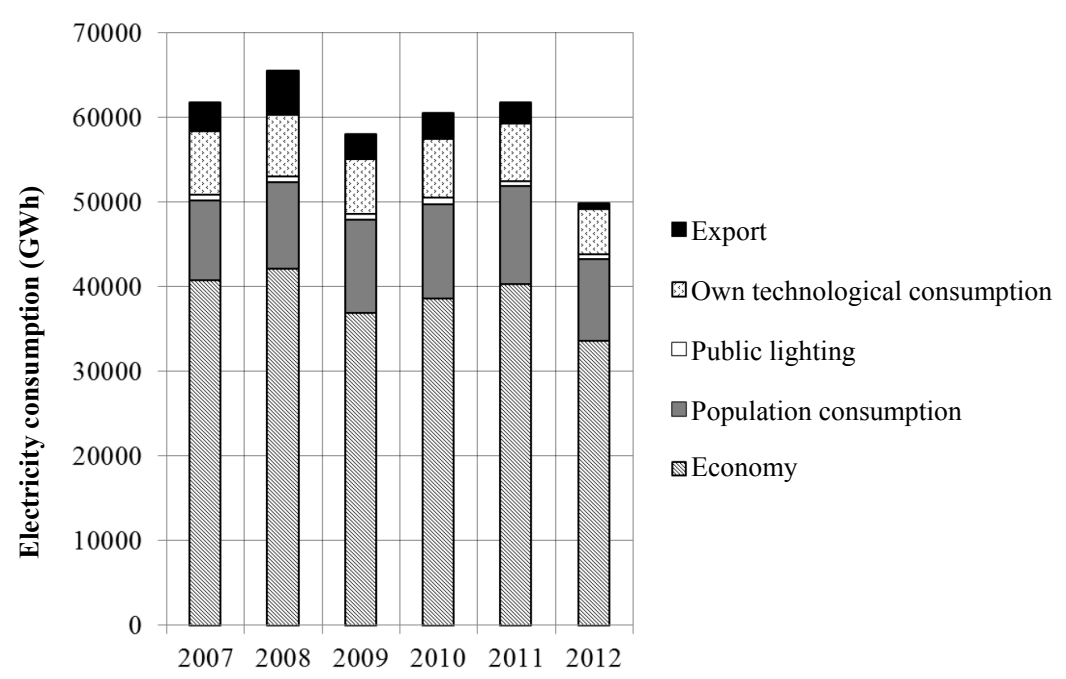

Figure 1: Electricity consumption (GWh) evolution in the last six years [5].

In Romania the electricity is generated in classic thermal power plants, hydropower and nuclear plants and wind and photovoltaic farms. The generation structure of National Power Grid (NPG) is annual, monthly and hourly variable, comprising about $17 \%-30 \%$ hydropower, $19 \%-24 \%$ nuclear, $0.4 \%$ liquid, $12 \%-$ $26 \%$ gas, $24 \%-41 \%$ solid and $3.7 \%-6.5 \%$ wind [ 4 ].

The structure of energy consumption, as it is shown in fig. 1, indicates an average of $65 \%$ in economy, $17.7 \%$ for population energy consumption, $1.1 \%$ in public lighting, $11.3 \%$ as export energy and $4.9 \%$ as own technological consumption in networks and power stations.

The evolution of the main resources for primary energy (fig. 2) shows that the resources are decreasing and domestic production tends to follow this trend, too [5].

Despite big investment in the field of hydropower production made in Romania over the last 60 years and the new regulations concerning the necessity of implementing modern and environmentally-friendly solutions in power system, the supremacy of traditional ways of gaining energy is still clearly visible. The largest share in electricity production belongs to fossil fuels $(32.3 \%)$ and nuclear fuels $(19.0 \%)$. The time related evolution of energy in the last six years (fig. 3) shows that this production is still dominated by classic thermalpower plants even if in the last two years the wind energy production had a rapidly growth. Also, the amount of energy produced in hydro-power plants is about the same with that one produced in the nuclear-plant.

The percent from total Power System in Romania, for each type of energy, are very different hourly, as a consequence of primary energy fluctuation in time. Table 1 gives the values of these installed capacities (MW) and the percent from total Romanian National Power Grid (NPG), for two days, in March 2013. 


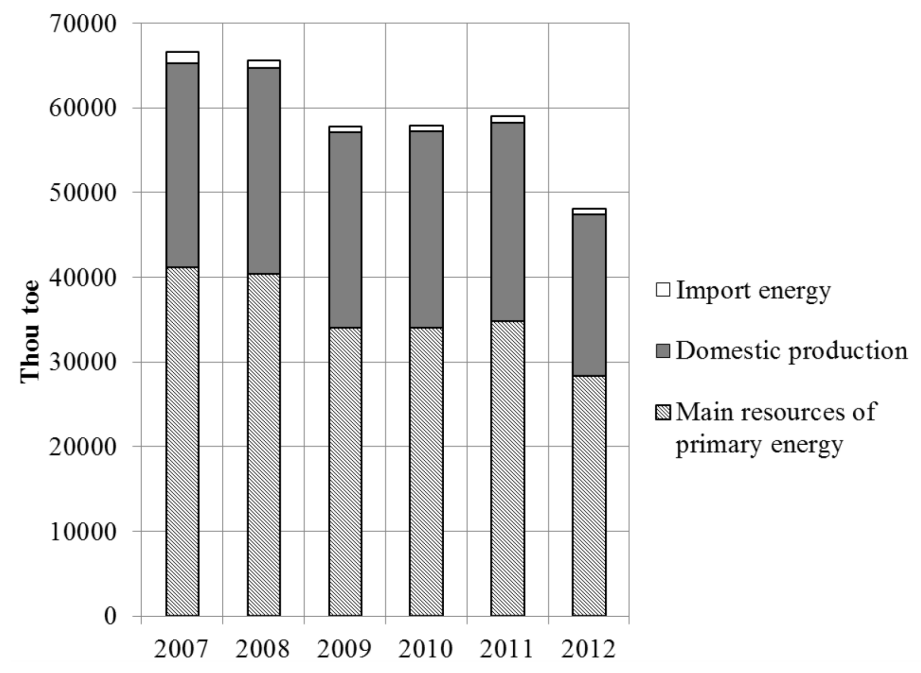

Figure 2: $\quad$ Main resources of primary energy compared with domestic energy production and imported energy, in Thou toe (tones oil equivalent).

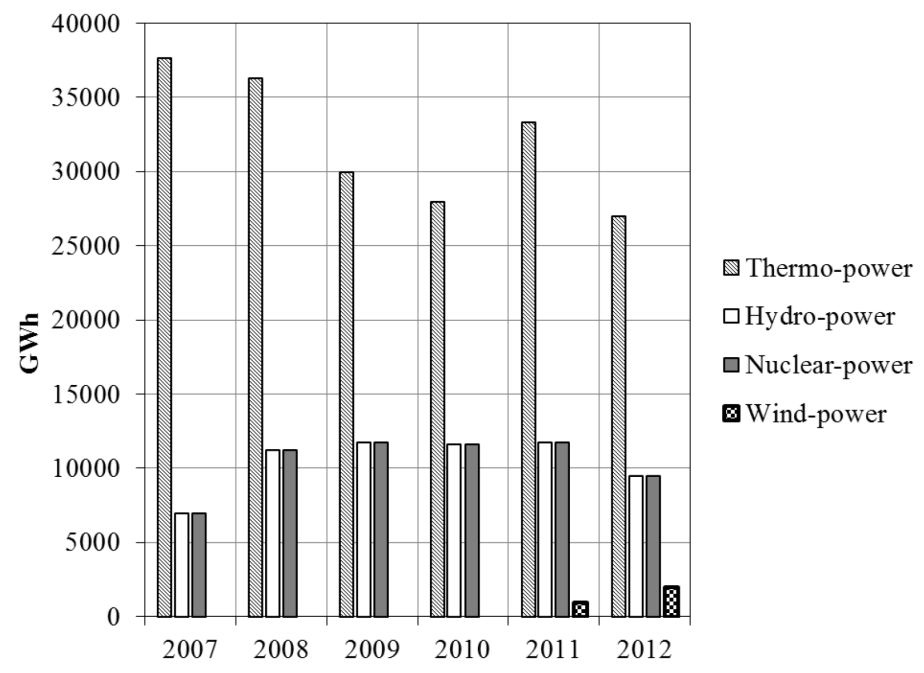

Figure 3: $\quad$ Electricity production evolution between 2007 and 2012 [5].

Power generation with wind and sun depends on natural conditions. Fluctuating renewables cannot be simply integrated in the NPG as it is now, which was conceived for centralised fuel-based power generation. Dealing with this fluctuation has become the central issue of the transition towards renewables.

Like an answer to the Renewable Energy Directive (2009/28/EC), the basic legislation related to development of renewable energies in UE, each Member 
Table 1: Romanian National Power Grid in real time for two days in $2013[6]$.

\begin{tabular}{|l|c|c|c|c|}
\hline \multirow{2}{*}{ Energy Type } & \multicolumn{2}{|c|}{ Day: 02.03.2013, hour: 22:45:01 } & \multicolumn{2}{c|}{ Day: 04.03.2013, hour: 11:14:01 } \\
\cline { 2 - 5 } & $\begin{array}{c}\text { Power into } \\
\text { NPG (MW) }\end{array}$ & $\begin{array}{c}\text { Percent from } \\
\text { Total Power (\%) }\end{array}$ & $\begin{array}{c}\text { Power into } \\
\text { NPG (MW) }\end{array}$ & $\begin{array}{c}\text { Percent from } \\
\text { Total Power (\%) }\end{array}$ \\
\hline Fossil fuels & 1,603 & 24.5 & 2,401 & 32.3 \\
\hline Hydrocarbures & 1,675 & 25.6 & 909 & 12.2 \\
\hline Nuclear fuels & 1,419 & 21.7 & 1,412 & 19.0 \\
\hline Hydropower & 1,614 & 24.7 & 2,234 & 30.0 \\
\hline Wind & 232 & 3.5 & 481 & 6.5 \\
\hline Total & 6,543 & 100 & 7,437 & 100 \\
\hline
\end{tabular}

State had to provide a National Renewable Energy Action Plan (NREAP) as requested the $4^{\text {th }}$ Article of the Directive. The Romanian NREAP defines the policy of renewable energy development in the context of the economic phenomena of transition from centralized economy to market economy.

The type of resources and the theoretical energy potential of renewable energy sources (RES) in Romania are mentioned in table 2.

Table 2: $\quad$ Theoretical energy potential of RES, in Romania [7].

\begin{tabular}{|c|c|c|c|c|}
\hline \multicolumn{2}{|c|}{$\begin{array}{c}\text { Renewable Energy } \\
\text { Source }\end{array}$} & $\begin{array}{c}\text { Annual Energy } \\
\text { Potential }\end{array}$ & $\begin{array}{c}\text { Economic } \\
\text { Energy } \\
\text { Equivalent } \\
\text { (Thou. toe) }\end{array}$ & Energy type \\
\hline \multirow{2}{*}{$\begin{array}{l}\text { Solar } \\
\text { energy }\end{array}$} & thermal & $6010^{6} \mathrm{GJ}$ & $1,433.0$ & thermal energy \\
\cline { 2 - 5 } & photovoltaic & $1.2 \mathrm{TWh}$ & 103.2 & electrical energy \\
\hline \multicolumn{2}{|c|}{ Wind energy } & $23 \mathrm{TWh}$ & $1,978.0$ & electrical energy \\
\hline \multirow{2}{*}{$\begin{array}{c}\text { Hydro- } \\
\text { energy }\end{array}$} & $\leq 10 \mathrm{MW}$ & $40 \mathrm{TWh}$ & $3,440.0$ & electrical energy \\
\cline { 2 - 6 } & $\leq 10 \mathrm{MW}$ & $6 \mathrm{TWh}$ & 516.0 & electrical energy \\
\hline \multicolumn{2}{|c|}{ Biomass } & $31810^{6} \mathrm{GJ}$ & $7,597.0$ & thermal energy \\
\hline \multicolumn{2}{|c|}{ Geothermal energy } & $710^{6} \mathrm{GJ}$ & 167.0 & thermal energy \\
\hline
\end{tabular}

Only RES electrical energy (RES-E) is further analysed. Sustainable development of electric energy in Romania is sustained and balanced by RES electrical energy development. From this point of view the NREAP's general objectives [7] for the operation of RES are designed to be sustainable for the national energy system because RES-E must be integrated in it. Also, RES-E must guarantee the independence of energy consumption for the national economy and must guarantee electric energy supply for isolated communities by using local renewable energy sources potential (table 3 ).

Table 3: $\quad$ Installed capacity and number of units/plants in RES-E in 2012.

\begin{tabular}{|l|l|l|}
\hline RES-E & Installed Capacity (MW) & Number of units \\
\hline Hydropower (SHP) & 427 & 314 SHP \\
\hline Wind & 1905 & more than 50 W farms \\
\hline Photovoltaic & 49 & 15 PV farms \\
\hline
\end{tabular}


We will analyse the RES-E evolution in recent years, in Romania, considering only Small Hydropower Plants (SHP), Wind farms (W) and Photovoltaic farms (PV).

Managing loads and achieving a good match between power consumption and weather-dependent power production will likely become a key issue.

\section{Small hydropower plants in Romania}

Hydropower is statistically the most common form of renewable energy and plays a very important role in the global energy production. Hydropower can be regarded as a relatively non-invasive to the surrounding environment, especially in the form of Small Hydropower Plants (SHP), what resulted in great popularity of this segment of green energy sector.

According to the International Energy Agency (IEA) [8] the global generation of electricity from hydropower in 2010 was 3,402.3 TWh, which accounted for almost $17 \%$ of total global energy production. The global technical potential is estimated at more than 16,400 TWh/year (Zimmy Jacek et al. [9])].

In order to show the current trend in hydropower development in Romania, the distribution of Hydropower Plants (HPP) electricity production in the last decades needs to be presented (fig. 4). In the last years an electricity production regression occurred, caused by economic factors and unfavourable hydrological conditions.

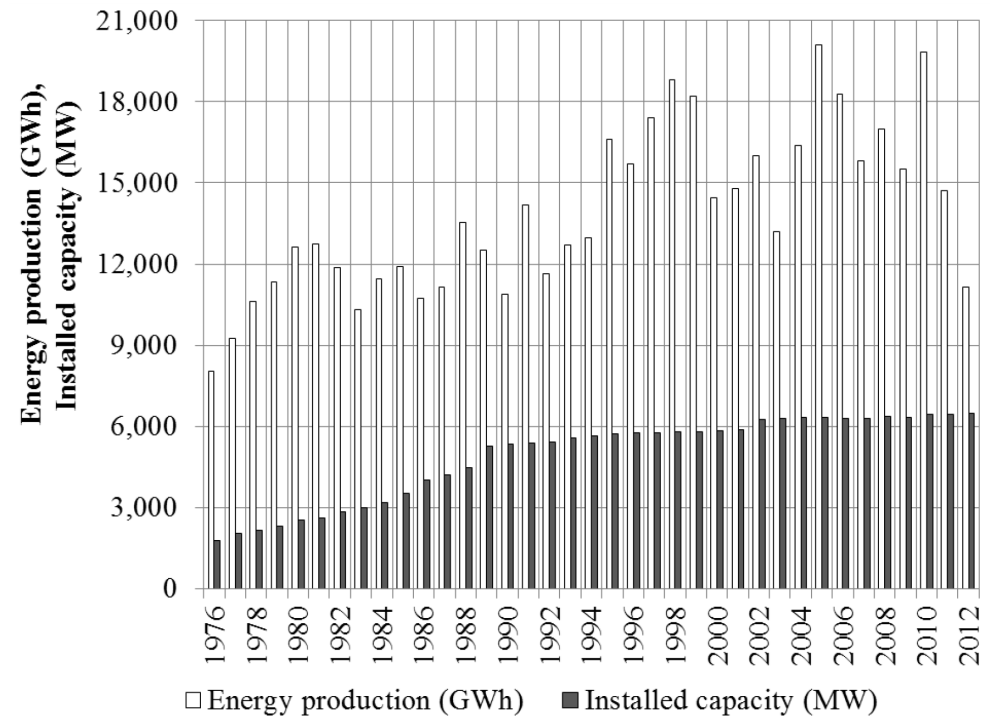

Figure 4: Evolution of installed capacity in Romanian HPP, and its energy production between 1976 and 2012 [10].

Analysing the problems of hydropower development one must distinguish between so-called large, and small hydropower. The border between them is 
determined by the value of the installed capacity (for SHP is less than or equal to $10 \mathrm{MW})$.

In Romania the hydropower technically feasible potential is $34 \mathrm{TWh} /$ year, with $23.3 \mathrm{TWh} /$ year $(68.5 \%)$ on the interior rivers, and $10.7 \mathrm{TWh} /$ year on the Danube River. Technically feasible potential of SHP is estimated at about 4,078 GWh/year (1,134 MW) [10].

Until 2008, 87 SHP private -owned with an average installed capacity of 65.27 MW produced an annual energy of $96.53 \mathrm{GWh} /$ year, depending on hydrological factors. The number of SHP increase in 2012 at 314 with $427 \mathrm{MW}$.

SHP hold a $1.28 \%$ share in electricity production in Romania.

The local character of SHP has several advantages, such as: they can be installed on small watercourses, with a relatively fast process of implementation (2-3 years) with materials and technologies already known; small structural and mechanical complexity; high durability and reliability; big capability to control the process shortening of energy transfer.

SHP projects are generally environmental friendly and non-polluting, because these projects do not involve construction of dam and therefore, no environmental rehabilitation problems arise.

Some of the inconveniences slowing new SHP projects down are: changes in natural flow regime with implication in solid flow, silting of channels carrying water, and administratively long and complicated bureaucratic procedures.

In Romania there is a huge interest for using the small hydropower potential. Due to European legislation, the production of energy using renewable energy sources is highly encouraged by the state and becomes extremely attractive for investors.

Problems as: design methodologies for the intelligent management and control, develop methodologies for the security of water distribution, investigate wireless sensor network based solutions for monitoring and control are extremely important for SHPs because of their specificity to be installed far from civilisation and in good connection with water use for other purposes than electricity, as: water supply, irrigation, fisheries.

\section{Wind and photovoltaic energy resources in Romania}

With a wind power potential of around $14 \mathrm{GW}$, an energy generating capacity of 23 TWh and a robust support scheme of Green Certificates, GC, (with 2 Green Certificates for one MW produced and delivered into the network), in the last two years wind energy in Romania has been growth faster than NREAP's estimations shown in fig. 5. Romania tends to become one of the leading users of wind power in Eastern Europe.

Dobrogea, Moldova and Banat have the biggest wind energy potential in Romania. In Dobrogea the average wind speed can reach 7 to $8 \mathrm{~m} / \mathrm{s}$ at an altitude of $100 \mathrm{~m}$. The region is flat, with low population density making possible to install a large number of wind turbines. From 992 MW installed capacity in all the country in 2012, 864 MW where installed in Constanta and Tulcea County. Fantanele-Cogealac Wind farm (built by CEZ Group) is the largest onshore wind 


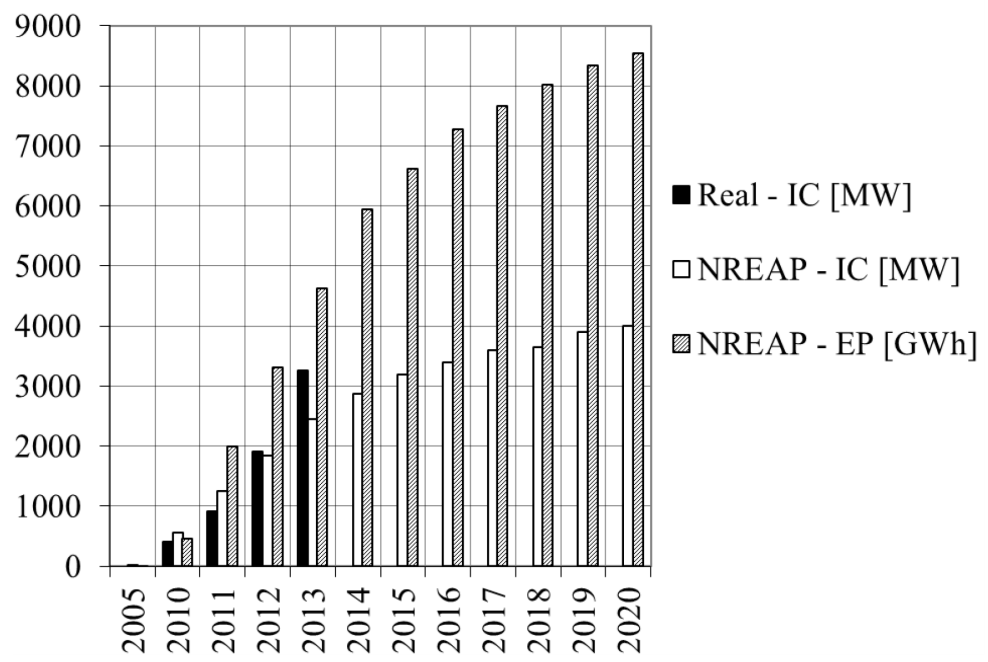

Figure 5: Real and projected total wind installed capacity (IC) in MW and projected total wind energy production (EP) in GWh [7].

farm in Romania with $600 \mathrm{MW}$ installed capacity. Covaci Solar Park is Romania's biggest PV farm with a capacity of $35 \mathrm{MW}$.

Located at the intersection of Central and Southeastern Europe, Romania has 210 sunny days per year with an annual energy flux between $1000 \mathrm{kWh} / \mathrm{m}^{2}$ and $1300 \mathrm{kWh} / \mathrm{m}^{2}$. Best locations in terms of solar radiation are the Black Sea shore, Dobrogea and Oltenia with 1450 to $1750 \mathrm{kWh} / \mathrm{m}^{2}$ [11].

Considering that the support scheme for solar PV energy is more generous, given 6 Green Certificates for each MWh produced and delivered into the grid, obviously the NREAP projected figures described in fig. 6, for solar PV installed capacity and electricity generation will be exceeded.

\section{State funding and subsidy}

The state plays an important role in the entire electrification process-policy making, strategy development and delivery. Countries have relied on different strategies to record different levels of success, but the electrification process has heavily dependent on government subsidies, which sometimes goes against sustainable solutions [12].

The Romanian National Energy Strategy for the period 2007-2020 provide to reduce energy dependence on imported fossil fuels, to ensure security of energy supply and to reduce the energy price risk. Renewable Energy Law, (Law no 220/2008), established the legal framework for the expansion of RES utilisation, and the support scheme to promote RES-E in Romania.

Romania's renewable incentive scheme is based on a system of Green Certificates (GC) with mandatory quotas. A Green Certificate represents a support form for the electricity produced from RES. Suppliers of electricity need 


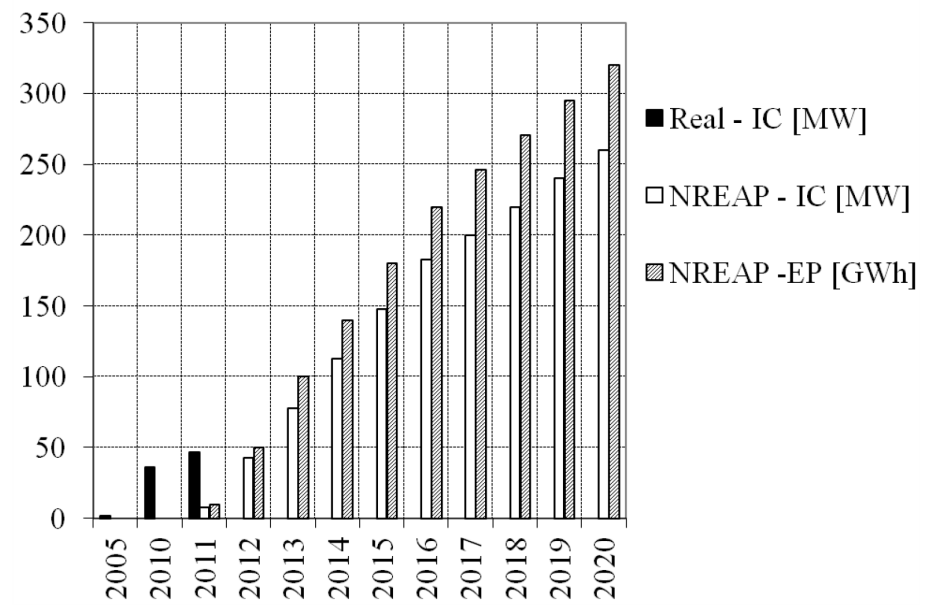

Figure 6: Real and projected total electric installed capacity, IC, (MW) and electricity production, EP, in photovoltaic units (GWh) [7].

to purchase annually a number of GC according to the mandatory quotas imposed by Law 220/2008. Mandatory quotas increased from $0.7 \%$ in 2005 to $8.3 \%$ in 2010 and are supposed to be $20 \%$ in 2020 . The producers receive for each unit of electricity delivered (1 MWh) into the grid a number of GC which can be traded exclusively on Green Certificates Market. The suppliers of electricity have to own a number of GC corresponding with the quota of electricity produced from imposed RES. The price of electricity sold is determined on the electricity market and the price of GC is determined by market mechanism [13].

The price of GC varies in a range of a minimum price imposed to protect the producers and a maximum price to protect the consumers. In 2012 Green Certificates "are traded between 121.89 RON (around $€ 28$ ) and 248.3 RON (around € 57.4)" [1].

In the Green Certificates scheme are assigned $6 \mathrm{GC}$ for solar PV energy, $3 \mathrm{GC}$ for small hydropower less than $10 \mathrm{MW}$ if the SHP is new and 2 GC if SHP is refurbished and 2 GC for wind energy till 2017 and then 1 GC between 2018 and 2025 .

\section{Sustainability of renewable energy production in Romania}

Defining sustainable development as a dynamic process, which enables all people to realize their potential and to improve their quality of life in ways which simultaneously protect and enhance the earth's life support systems, three elements of sustainable development (environment, society, and economy) have to be in a permanent perfect correlation. The social and environmental dimensions must be balanced with economics. 
We try to provide an overview of the sustainability in a way that is relevant to electric power production and focusing on green energy specific problems.

To quantify the best method to obtain energy among SHP, Wind and PV farms, we generate a "Score matrix" considering the most important criteria which define the sustainability of these processes. For each of the three methods, is given a score which reflects how well they accomplish the sustainability criteria ( 0 for the worst method and $10 \sqrt{3},(17.32)$ for the best). The wining method and the most sustainable solution will be the one with the maximum "FINAL SCORE".

The steps of this method are the following:

1. selecting the criteria (SC) and sub-criteria (SSC) that describe the sustainability of SHP, W and PV;

2. scale-setting for criteria evaluation (FINAL SCORE will be unsatisfactory for values between 0 and $(10 \sqrt{3})(1 / 4)$, satisfactory for $(10 \sqrt{3})(1 / 4)-(10 \sqrt{3})(2 / 4)$, good for $(10 \sqrt{3})(2 / 4)-(10 \sqrt{3})(3 / 4)$, and very good rating for $(10 \sqrt{3})(3 / 4)-10 \sqrt{3})$;

3. granting importance coefficients for each sub-criterion -ICSC(i);

4. assigning a "mark" between 1 and 10 -M(i), for each renewable technology, considering the assessment of its capability to accomplish the sustainability, SSC(i), of a sub-criterion ;

5. calculate the "SCORE" for each sub-criterion multiplying the "mark" $(\mathrm{M})$ by its importance coefficient (ICSC);

$$
\operatorname{SCOR}(\mathrm{i})=\operatorname{ICSC}(\mathrm{i}) \times \mathrm{M}(\mathrm{i})
$$

6. the total "SCORE" for a criterion will be the sum of sub-criteria "SCORES" SSCS(i). In our example, presented in table 4, "Technical and Economical" Sustainability Criterion (SC-TE) will have a score "Total SC-TE- SCOR" obtained by the sum of sustainability sub-criteria SSCTE(i):

$$
\text { Total SC }-\mathrm{TE}-\mathrm{SCOR}=\sum_{\mathrm{i}=1}^{12} \operatorname{SSCTE}(\mathrm{i}) \text {, }
$$

"Environmental" Sustainability Criterion (SC-E) will have a Score "Total SC-ESCOR" obtained by the sum of sustainability sub-criteria SSCE(i):

$$
\text { Total SC }- \text { E - SCOR }=\sum_{i=1}^{6} \operatorname{SSCE}(\mathrm{i}) \text {, }
$$

"Social and institutional" Sustainability Criterion (SC-SI) will have a Score "Total SC-SI- SCOR" obtained by the sum of sustainability sub-criteria $\operatorname{SSCSI}(\mathrm{i})$ :

$$
\text { Total SC -SI - SCOR }=\sum_{i=1}^{5} \operatorname{SSCSI}(\mathrm{i})
$$


Table 4: $\quad$ Scores Matrix of RES-E sustainability.

\begin{tabular}{|c|c|c|c|c|c|c|c|c|}
\hline & \multicolumn{2}{|c|}{ Sustainability criteria (SC) and ICSC } & \multicolumn{3}{|c|}{ MARK } & \multicolumn{3}{|c|}{ SCORS } \\
\hline & Sustainability sub- criteria (SSC) & ICSC & SH & $\mathrm{W}$ & & & & \\
\hline & & & & & PV & SH & W & PV \\
\hline \multirow{2}{*}{ 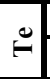 } & SSCTE (1). Initial investments & 0.1 & 6 & 8 & 7 & 0.6 & 0.8 & 0.7 \\
\hline & SSCTE (2). Profitability & 0.1 & 6 & 8 & 7 & 0.6 & 0.8 & 0.7 \\
\hline \multicolumn{3}{|c|}{ Sustainability criteria (SC) and ICSC } & \multicolumn{3}{|c|}{ MARK } & \multicolumn{3}{|c|}{ SCORS } \\
\hline & $\begin{array}{l}\text { SSCTE (3). Technological } \\
\text { complexity }\end{array}$ & 0.1 & 7 & 8 & 6 & 0.7 & 0.8 & 0.6 \\
\hline & SSCTE (4). Cost effectiveness & 0.1 & 10 & 7 & 8 & 1 & 0.7 & 0.8 \\
\hline & $\begin{array}{l}\text { SSCTE (5). Capital cost burden on } \\
\text { the user }\end{array}$ & 0.1 & 5 & 5 & 5 & 0.25 & 0.25 & 0.25 \\
\hline & SSCTE (6). Natural potential & 0.1 & 5 & 10 & 2 & 0.5 & 1 & 0.2 \\
\hline & SSCTE (7). Technical efficiency & 0.1 & 10 & 9 & 8 & 1 & 0.9 & 0.8 \\
\hline & SSCTE (8). Reliability of supply & 0.05 & 10 & 8 & 9 & 1 & 0.8 & 0.9 \\
\hline & SSCTE (9). Fatigue damage & 0.05 & 7 & 8 & 9 & 0.35 & 0.4 & 0.45 \\
\hline & SSCTE (10). Market growth & 0.1 & 7 & 9 & 9 & 0.7 & 0.9 & 0.9 \\
\hline & SSCTE (11). Dependence on clime & 0.05 & 8 & 6 & 7 & 0.4 & 0.3 & 0.35 \\
\hline & SSCTE (12). Lifetime & 0.05 & 10 & 9 & 8 & 0.5 & 0.45 & 0.4 \\
\hline & Total SC-TE- SCOR & 1 & - & - & - & $\overline{7.6}$ & 8.1 & 7.05 \\
\hline \multirow{7}{*}{ 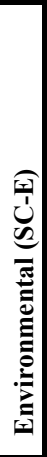 } & $\begin{array}{l}\text { SSCE (1). Contribution to reduction } \\
\text { in } \mathrm{CO}_{2} \text { emission }\end{array}$ & 0.2 & 5 & 10 & 2 & 1 & 2 & 0.4 \\
\hline & $\begin{array}{l}\text { SSCE (2). Contribution to reduction } \\
\text { land degradation }\end{array}$ & 0.15 & 8 & 7 & 6 & 1.2 & 1.05 & 0.9 \\
\hline & $\begin{array}{l}\text { SSCE (3). Contribution to reduction } \\
\text { water pollution }\end{array}$ & 0.15 & 8 & 10 & 10 & 1.2 & 1.5 & 1.5 \\
\hline & $\begin{array}{l}\text { SSCE (4). Contribution to reduction } \\
\text { impact on fauna, flora }\end{array}$ & 0.15 & 6 & 6 & 6 & 0.9 & 0.9 & 0.9 \\
\hline & $\begin{array}{l}\text { SSCE (5). Contribution to reduction } \\
\text { of noise distribution }\end{array}$ & 0.15 & 8 & 5 & 10 & 1.2 & 0.75 & 1.5 \\
\hline & $\begin{array}{l}\text { SSCE }(6) \text {. Power yield per unit area } \\
\text { of land required }\left(\mathrm{W} / \mathrm{m}^{2}\right)\end{array}$ & 0.2 & 10 & 7 & 5 & 2 & 1.4 & 1 \\
\hline & Total SC-E- SCOR & 1.0 & & & & 7.5 & 7.6 & 6.2 \\
\hline \multirow{7}{*}{ 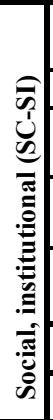 } & $\begin{array}{l}\text { SSCSI (1). Working place in } \\
\text { construction period }\end{array}$ & 0.2 & 10 & 9 & 8 & 2 & 1.8 & 1.6 \\
\hline & SSCSI (2). Need for skilled staff & 0.2 & 9 & 10 & 10 & 1.8 & 2 & 2.0 \\
\hline & $\begin{array}{l}\text { SSCSI (3). Need for micro-credit or } \\
\text { financial support systems }\end{array}$ & 0.2 & 8 & 7 & 6 & 1.6 & 1.4 & 1.2 \\
\hline & $\begin{array}{l}\text { SSCSI (4). Ability to protect } \\
\text { consumers }\end{array}$ & 0.2 & 8 & 0 & 6 & 1.6 & 2 & 1.2 \\
\hline & $\begin{array}{l}\text { SSCSI (5). Ability to protect } \\
\text { investors }\end{array}$ & 0.2 & 8 & 6 & 10 & 1.6 & 1.2 & 2.0 \\
\hline & Total SC-SI- SCOR & 1.0 & & & & 8.6 & 8.4 & 8.0 \\
\hline & FINAL SCORE & & & & & 13.7 & 13.9 & 12.3 \\
\hline
\end{tabular}


Considering the above sustainability three criteria like coordinates in a three dimensional Cartesian system, the "FINAL SCORE" of each RES from table 4 will give us the position of SHP, W or PV sustainability in a cube with dimensions $[10,10,10]$, and the diagonals equal to $10 \sqrt{3}$. A "FINAL SCORE" $=17.32$ will characterise the best sustainability, and zero- the worst one. In table 4 we calculated the "FINAL SCORE" for SHP, W and PV (like a root mean square of TotalSC's values) with the relation:

FINAL SCORE $=$

$$
\sqrt{(\text { Total SC - TE - SCOR })^{2}+(\text { Total SC - E - SCOR })^{2}+(\text { Total SC - SI - SCOR })^{2}}
$$

for $12 \mathrm{SSCTE}, 6 \mathrm{SSCE}$, and 5 SSCSI chosen to describe in an general manner the RES sustainability. Different scenarios can be estimated changing the subcriteria, the importance coefficients for each sub-criterion -ICSC(i) or the mark for each RES. According to our score matrix, the winning solution was W, suggesting that the most sustainable solution to obtain electrical energy, in Romania is from Wind power farms. This result obtained for RES-E must be correlated and harmonized with the structure of NPG to finally obtain a sustainable development of electric energy in Romania.

\section{Conclusions}

This paper tries to realise an overview on the growth of new energy capacities using renewable sources in Romania and proposes a method to analyse the sustainability of RES, for the most important type of renewable energy technology used to generate electricity (SHP, W, PV).

Obviously, governments should approach energy efficiency from the perspective of a rigorous assessment of their own national interest. This means that policy stance is established based on the overall appreciation of the risks, costs and benefits of adopting, promoting and instituting energy efficiency interventions. With the implementation of the relevant legislative and economic support the green-energy methods can provide an excellent alternative and complement to the non-renewable energy on a local level. Adapting quickly to new technologies and complying with new regulations are important in ensuring resilience, relevance, and long term sustainability. National interest should be considered in a multi-dimensional way that includes long-term considerations based on a detailed scientific, economic and political assessment.

\section{References}

[1] EU Energy in figures 2010. Greenhouse Gas (GHG) Emissions by Sectors. European Commission. Directorate-General for Energy and Transport (DG-TREN), www.ec.europa.eu/energy/publications/doc/statistics/ext_ greenhouse_gas_emissions_by_sector.pdf. 
[2] Eastern Winds. Emerging European Winds Power Markets, A report by the EWEA, February 2013.

[3] Delina, Laurence L. Coherence in energy efficiency governance, Energy for Sustainable Development 16, pp. 493-499, Elsevier, 2012.

[4] Monthly Reports of Generators, ANRE, Oct., 2012, www.anre.ro

[5] Industry Statistical Bulletin, Romanian National Institute of Statistics, ISSN 2066-0707, www.insse.ro.

[6] www.transelectrica.

[7] Romanian National Renewable Energy Action Plan (NREAP), Bucharest 2010, http://www.ecn.nl/nreap.

[8] International Energy Agency, www.iea.org.

[9] Zimny Jacek, P. Michalak, S. Bielik, K. Szczotka, Directions in development of hydropower in the world, in Europe and Poland in the period 1995-2011, Renewable and Sustainable Energy Reviews, 21, pp. 117-130, 2013.

[10] Hidroelectrica Annual Technical Reports 1976-2012.

[11] Barla E., Badea G.E., Porumb C., Photovoltaic potential from solar database evaluation, Journal of Sustainable Energy, Vol. 1, No. 1, pp. 28312010.

[12] Meadowcroft J., Climate change governance, Policy Research Working Paper No 4941, Washington, DC: The World Bank, 2009.

[13] Romanian power market operator, www.opcom.ro. 